\title{
Research on the construction mode of excellent teaching team based on systematic thinking of Complexity Science Management
}

\author{
Li Shengnan \\ School of Economics and Management \\ Northeast Dianli University \\ Jilin, China \\ e-mail:1419910719@qq.com
}

\author{
Lin Zhouzhou \\ School of Economics and Management \\ Northeast Dianli University \\ Jilin, China \\ e-mail: 627609305@qq.com
}

\author{
Zhang Hongjing \\ School of Economics and Management \\ Northeast Dianli University \\ Jilin, China \\ e-mail: zhanghongjing001@ sina.com
}

\begin{abstract}
Existing literature on the excellent teaching team have confined mostly to the team structure, the quality and requirements of the leaders, young teachers' training and other routine issues. However, they have little researched the operation mode and development strategy of excellent teaching team. It is not conducive to improve the construction of teaching team. According to the discovery of the problem and based on the introduction of Complexity Science Management, this article has analyzed the complexity of excellent teaching team by using the Complexity Science Management system. And it has proposed three aspects of the measures, including establishing effective operation mode of team, establishing a reliable safeguard system of teaching team and establishing scientific development strategy of teaching team. These measures will lay the foundation to integrate resources and complete goals for team. They are conducive to perfect the construction mode of excellent teaching team.
\end{abstract}

Keywords-Complexity Science Management; excellent teaching team; complexity; operation mode; development strategy

\section{INTRODUCTION}

In recent years, with the continuous expansion of China's higher education scale, how to ensure the teaching quality of higher education has become the forefront of higher education major and urgent task. As the planners and implementers of higher education, the teaching team is very important to ensure the teaching quality of higher education. Especially, since the ministry of education and ministry of finance jointly launch quality engineering, various universities view teaching team construction as the focus of the project to guarantee and improve teachers' quality, teaching ability and teaching quality of education in colleges and universities. Therefore, how to construct purposefully teaching team, establish an effective team cooperation mechanism and promote the exchange of teaching and teaching experience are the key link to promote discipline construction, strengthen the construction of teachers' team and promote the sustainable development of the school. Excellent teaching team is not only characteristic of teachers' team construction in colleges and universities and the important strength to improve the personal qualities of teachers, teaching ability and the quality of teaching, but also has important effect to improve the teaching quality of college education.

Wei Wei (2012) argued that schools should provide comprehensive, multi-level support. It involved in the teaching construction, teaching reform, structuring the platform of growth and development of outstanding teaching team by professional construction[1]. Wu Hui and Jin Hui (2013) suggested that young teachers' professional development was the key factor of teacher team construction in colleges and universities. They suggested the environment mechanism should be constructed to promote the development of young teachers' professional. On the basis of the analysis of the status of young university teachers team construction, they pointed out the effective elements of its construction and put forward to three aspects of strategy to strengthen the team construction goal, setting up academic exchange platform and perfecting examination management mechanism[2]. Li Xianling and Zhang Datian (2014) argued that the construction of excellent teaching team need to develop clear reasonable teaching goal, creating a good team culture, forming a reasonable team structure, establishing a suitable teaching team leader and providing powerful teaching team [3].

Comprehensively analyzing literature, the current study of outstanding teaching team focuses on system construction. The scope and content of discussion mostly are confined to the team structure, the quality and requirements of the leader, training of young teachers and other routine problems. While teaching team construction research on some theoretical issues have made many achievements, these results have a positive 
guiding significance for teaching team construction in colleges and universities, but these researches lag far behind rich and complex teaching team construction. These researches content a lack of new growing points. How to effectively carry out team building operation mechanism, strengthen the cooperation ability, develop scientific development strategy are not conducive to expanding and deepening the research on teaching team construction. Therefore, according to the problems found, this article has studied a complex system of excellent teaching team construction which combined with Complex Scientific Management theory in system thinking way. It has put forward to some suggestions on view of the operation mode and the scientific development strategy about teaching team. It will enrich the theory connotation of teaching team construction and infer the development rules of outstanding teaching team to give full play to its theoretical guidance.

\section{INTRODUCTION TO THE THEORY OF COMPLEXITY SCIENCE MANAGEMENT}

According to a new thinking mode and a new observation problem, the CSM is based on the complex science and management science to fusion and development. The complexity system includes management thinking, management theory and management methods [4].

Complexity Science Management considers that: (1) the complex systems of social dimension is the involvement of people with their thinking. (2) Some individuals in complex systems have randomness, uncertainty and nonlinear. It is mutual influence and evolving among individuals. The system itself and its components have interaction with the environment. (3) The complex system has multi-level structure and each level economic benefit is not usually the same. It needs to coordinate. (4) The components of complex system have intelligence, that is, the composition of complex system contains the experience, wisdom and thinking of the experts. (5) Complex system has Self-organization, Self-Adaptation and Dynamic.

\section{THEORETICAL BASIS OF EXCELLENT TEACHING TEAM BUILDING}

As a form of social organization, teaching team is complex system engineering. Complex science provides a scientific methodology basis for the theoretical research on the construction of excellent teaching team. It expands the new horizons and provides a new way for its construction so that we can achieve the best effect of teaching team and improve the construction mode of excellent teaching team.

\section{A. The complexity on the construction of excellent teaching team from the perspective of Complexity Science Management}

1) The complexity of excellent teaching team subject: University teachers are the subject of excellent teaching team and their complexities act that each subject is a complex selforganizing system. It shows the complex nature of the nonlinear feedback. University teachers represent a high level of intellectual groups and their development is more particularity. Firstly, university teachers' work characteristics. The independence of the university teachers determines that their autonomy is very strong. This feature is conducive to the formation of a unique teaching style, distinctive personality of university teachers, but it also often lead that the teachers used to teaching activities alone. It makes the exchange time little between colleagues and lack mutual communication so that teachers lack team awareness. Secondly, teaching team members have presented internal conflicts. There are competitions among teachers, leading a team of internal conflict. The object of conflicts can be interests, values, goals, personality and so on in many aspects. These phenomena will inevitably lead to the internal friction of the teachers, the lack of team spirit, resulting in the overall quality of teachers to upgrade. They are not conducive to the sustainable development of teaching team, hinder the progress of teaching reform and seriously affect the teaching quality and effect.

2) The complexity of excellent teaching team process: The complexity on the construction of excellent teaching team is a systematic work, including the determination of team goals, team leader selection, team structure and team culture. For example, some colleges and universities exist that the phenomenon is the director of department as the team leader, teachers of teaching and research section as team members. However, within the department, individual teacher role clearly and collective action weakly, teaching activities are teachers' individual combat. They do not achieve the support of other teachers experience and wisdom. The excellent teaching team pays more attention to the openness of the member selection, the synergy between the team members and the role of the team.

3) The complexity of excellent teaching team surroundings. Excellent teaching team building surroundings are divided into external surroundings and internal surroundings. The external surroundings include three hands. One is a strong support, which is not only the human, material and financial aspects, but also policy, mechanism and system level. Two is the scientific evaluation mechanism, that is, the overall evaluation of teaching team contains content, index and methods. Finally, it is a proper incentive and restraint mechanism, that is, the survival on the fittest of the teaching team and reward and punishment of target completion degree. The internal surroundings include scientific planning teaching team, rational selection of teaching team leader, the correct handling to the contradictions of team members, the construction of a harmonious mutual team culture and how to achieve the common development of team members.

\section{B. The construction of excellent teaching team based on the thinking mode of system}

The thinking mode of CSM is systematic thinking. It is a core of holistic view. It makes the integration of the various resources within the system and outside of the system. Then it can change the existing resources, changing the ability of existing resources to create wealth, changing the output of resources so that the system has become a competitive system. Their integration and collocation are very important. If integration and collocation are different, the results will be different [5]. 
The construction of excellent teaching team is a dynamic, specific and open framework. It is different from the general teaching team and it is the leader of many teaching team in universities. It is a large number of teaching teams to pursue the benchmark. On the one hand, the construction of excellent teaching team needs to achieve the abutment of overall strategy in national higher education. On the other hand, it needs to adapt the actual situation of the university in order to seek advantage of excellent teaching team to enhance innovation and competition. Under the system thinking mode, the construction of excellent teaching team is no longer bound by the opinion of quality engineering and the research content is no longer limited to the conventional problem. It has become an important way to encourage innovation, improved the teaching quality, the effective use of teaching team and the full play of its effectiveness.

\section{INSPIRATION OF THE CSM TO CONSTRUCTION MODE OF EXCELLENT TEACHING TEAM}

\section{A. Establish effective internal operation mode of teaching team}

1) Targets of scientific planning teaching team: Effective team goals can provide direction and motivation for team members, which make team members commit to the organization's goals. Having clear goals is not only the salient features of excellent teaching team, but also the foundation of team construction. The establishment of teaching team aims to integrate teaching resources, improving teaching level and strengthen the construction of teaching staffs [6].

Pay attention to the two problems when setting goals: Firstly, we must emphasis on sharing objective responsibility within organization. The team leaders put forward to the preliminary goals for team construction. They share goals among team members by wide and in-depth discussion and get consistent approval. Thus both organization and members all have clear goals respectively. This way of establishing organizational goals can produce a sense of belonging to team for its members, and motivate members to actively take responsibility, playing their own advantages and selflessly dedicate their knowledges by effective communications. Secondly, we can establish team goals responsibility system. After setting up team goals, team goals must be periodically decomposed and each part is specific, measurable and achievable. The establishment of the target responsibility system is the key to team success. The team needs to establish an internal management system including self-assessment, self-incentives and self-constraints. In the aspect of teachers' personal development, we should response to different teachers at different development goals to ensure that the classification of teacher development.

2) Pay attention to member conflict of teaching team: Team conflict refers to the process that opposition and divergence in goals, concepts, values, affections and interests appear between different team members, team members and organization, team and organization. These are interpersonal conflict, cognitive conflict, goal conflict and psychological conflict[7]. At present, the performance of teaching team conflict is divided into internal conflict and external conflict.
Strong similarities within the team members have decided that there must be conflict among them and it is not conducive to the stability of team building. The uneven distribution of resources, the irrational distribution of benefits and other factors have caused the conflict among the teams. We can build a unified standard within team and introduce appropriately team competition mechanisms to resolve conflicts. The unified standard can make university teachers recognize their own role and the location in the team. They realize mutual dependency relation. Competition mechanisms can enhance the unity and cohesion of team members, promoting the interaction of members and running in constantly.

3) Cultivate the core culture of harmonious cooperation: System culture is not only a kind factor of value incentive, but also a kind lever of interest stimulation. It not only touches the person's spirit value, but also touches people's reputation interest. It is the guarantee system to achieve the value target of teaching team[8]. Culture is the core of teaching team. Promote the construction of cultural system is beneficial to enhance the sense of belonging of university teachers to the teaching team and cultivate the core culture of harmonious cooperation. We can achieve the culture by adhering to the principle of people-oriented, building a platform for the exchange and learning of teachers, realizing the organic combination of material and spirit.

\section{B. Establish a reliable security system of teaching team}

1) Provide favorable external conditions: The survival and development of the team organization can not be separated from certain material conditions, including office space, facilities and daily operating expenses[9]. Whether it is professional development, teaching methods reform or internships, the construction of excellent teaching team both need safeguard human, material and financial resources. The construction of teaching team is a systematic project, which not only requires the cooperation of many departments, but also depends on the optimization and integration of teaching resources in different disciplines and departments. First of all, the school leaderships should provide the necessary personal, financial and material resources to team for completing the work. There are establishing special funds, giving the opportunities which contain outside learning and participating in domestic and international academic, purchasing teaching equipment. Secondly, we should establish the necessary rules and regulations. Rules and regulations not only have the function of restriction, but also have the function of guidance and encouragement. School must start from reality to make reasonable regulations, considering the nature of team. It ensures the subjective initiative of each team to achieve goals.

2) Establish the evaluation system of multi dimensional performance: Scientific and reasonable evaluation system is an effective way to mobilize the enthusiasm of the team, testing the results of its construction and improving the core competitiveness of team. It is an important guarantee for the orderly operation of the team. Performance evaluation is a kind of target management. What's more, it is a kind of process management. Many aspects assemble organic links to form a continuous, closed-loop management system. 
We can establish a scientific evaluation system of multi dimensional performance. Firstly, in the content of evaluation, one is the teacher's personal performance evaluation, mainly which refers to teacher's personal commitment to the task and the degree of completing target. Two is achieving team goals. Three is the contribution of individual teachers to team performance and the size of team's input and output. At last, we need to see competition and cooperation of the team. Secondly, in the method of evaluation, we should pay attention to the evaluation of authoritative departments and peers, but also pay attention to the evaluation of students and industry enterprises. Thirdly, in the process of evaluation, we should pay attention to the evaluation of the final results of the team construction, but also pay attention to the phased supervision and assessment of the construction process.

\section{Establish a scientific development strategy of teaching team}

1) Promote the interdisciplinary fusion of teaching team: Conducting teaching research between teachers and promoting teaching reform and undertaking a comprehensive program need the cooperation between teachers and between the organizations, the difference and the cross of professional knowledge determines the teaching team is willing to carry on deep discussion and communication with other different disciplines organization teachers .The cooperation of different disciplines teaching team is one of the best ways to reduce cost, to undertake large projects and give play to the role of interdisciplinary in colleges and universities is conducive to the sustainable development of the teaching team. In fact, there is the widespread phenomenon of independent development in teaching teams, who are reluctant to share their results with other team[10]. Despite teaching and academic exchange are hold in school regularly, they just go to form, no substantive progress. If setting a super goal, had enough appeal again and only relied on unilateral complete, they will try to unite. According to the needs of project, these teams proceed no regular exchanges, cooperating to complete project and achieve a win-win situation.

2) Carry out deep university-enterprise cooperation: Building teaching team and appealing to technical backbone and experts in industry and enterprise into teaching team make the school full-time teachers and the industry enterprise parttime teachers play their respective advantages and collaboration to comprehensively improve the quality of personnel training, which realize "win-win cooperation between colleges and enterprise, information resource sharing and two-way interaction of person with ability".

First, a university-enterprise cooperation conference should be held on a regular basis to listen to opinions and suggestions industry and enterprise staff; Second, enterprise technical experts should substantively participate in curriculum construction and be responsible for the part of the guidance of comprehensive practice training curriculum and teaching practice in campus, etc.; Third, we need to give play to the resource advantage of teaching team to provide technical services, personnel training and professional qualification appraisal for the enterprise and society to strengthen the link between colleges and enterprise.

\section{CONCLUSION}

The construction of excellent teaching team is a long-term project. Team building finished is not representative about the completion of excellent teaching team construction. Construction of excellent teaching team is to play itself in vanguard role of the teaching, teaching reform and teaching research. It is continuous to improve the quality of education and teaching. By analyzing the complexity on the construction of excellent teaching team within universities and thinking of complexity science management system, this article put forward to a number of recommendations to the operation mode and development strategy of excellent teaching team. In this paper, the inadequacies of study are the main theory, not listed specific cases. I suggest that further studies can make the Basic Pilot. We can make the CSM apply to the construction of excellent teaching team, and it can provide a reference for improving the construction of excellent teaching team.

\section{REFERENCES}

[1] Wei Wei. Cultivation and construction of excellent teaching team within universities [J]. Pop music Magazine, 2012(3): 80-81. (In Chinese)

[2] Wu Hui and Jin Hui. Study on the Promotion of Team Construction Mechanism of Young Teachers' Professional Development in Higher School [J]. Research in Education Development, 2013(17): 81-84. (In Chinese)

[3] Li Xianling and Zhang Datian. The construction of excellent teaching team in higher vocational colleges [J]. Education and Vocation, 2014(12): 67-68. (In Chinese)

[4] Cheng Siwei. Complex science and management [J]. Journal of Nanchang University, 2000,7(3): 45-67. (In Chinese)

[5] $\mathrm{Xu}$ Xusong and $\mathrm{Wu}$ Qiang. The frontier of management science: complexity science management [N]. Guangming daily, 2005.05.10(10). (In Chinese)

[6] Zhang Yuesong. On the operation mechanism and characteristics of the construction of teaching team in Colleges and Universities [J]. Journal of Shaoxing University, 2013(5): 1-3. (In Chinese)

[7] Wang Jie. Mechanism of team task conflicts effect on the team task performances [D]. Hangzhou: Zhejiang University,2009(5). (In Chinese)

[8] Hu Baicui. Systematic Assurance for the Construction of Excellent Teaching Staff Team of Higher Vocational Schools [N]. Vocational and technical education, 2011(11):62-65. (In Chinese)

[9] Teng Xiangdong and Ren Weining. An Analysis of the Construction Methods and Management Strategies for College Teaching Team [J]. Journal of Beijing Union University (Humanities and Social Sciences), 2009(11): 115-119. (In Chinese)

[10] Wang Yifen. Discussion on the construction of excellent teaching team in universities $[\mathrm{J}]$. Journal of Educational Institute of Jilin Province, 2010(3): 30-31. (In Chinese) 